\title{
Effect of Stress and Moisture Content on Permeability of Gas-Saturated Raw Coal
}

\author{
Junhui Wang, ${ }^{1}$ Zhijun Wan $\mathbb{D}^{1}{ }^{1}$ Yi Wang $\mathbb{D},{ }^{2}$ Zhixiang Liu, ${ }^{3}$ Sifei Liu, ${ }^{1}$ Hongwei Zhang $\left(\mathbb{D},{ }^{4}\right.$ \\ and Qiuyan Pei ${ }^{5}$ \\ ${ }^{1}$ Key Laboratory of Deep Coal Resource Mining (CUMT), Ministry of Education of China; School of Mines, China University of \\ Mining and Technology, Xuzhou, Jiangsu 221116, China \\ ${ }^{2}$ College of Safety and Emergency Management Engineering, Taiyuan University of Technology, Taiyuan, Shanxi 030024, China \\ ${ }^{3}$ Planning and Research Institute, Norinco Group, Beijing 100053, China \\ ${ }^{4}$ School of Energy and Mining Engineering, China University of Mining and Technology (Beijing), Beijing 100083, China \\ ${ }^{5}$ University of Science and Technology of China, Hefei, Anhui 230031, China
}

Correspondence should be addressed to Zhijun Wan; zhjwan@cumt.edu.cn and Yi Wang; wangyi@tyut.edu.cn

Received 9 April 2020; Accepted 17 June 2020; Published 7 September 2020

Academic Editor: Jingmin Xu

Copyright (C) 2020 Junhui Wang et al. This is an open access article distributed under the Creative Commons Attribution License, which permits unrestricted use, distribution, and reproduction in any medium, provided the original work is properly cited.

\begin{abstract}
Hydraulic fracturing and premining gas drainage are important to safe mining and coalbed methane extraction. These technical processes cause the redistribution of in-situ stress and the regional variation of moisture contents within the affected zone. Therefore, we investigated the coupled effect of variable stresses (from $9 \mathrm{MPa}$ to $27 \mathrm{MPa}$ ) and moisture contents (from $0.22 \%$ to $4.00 \%)$ on the permeability evolution of gas-saturated raw coal. The results show that (1) the relationship between the mean effective stress and the permeability can be described by a power function according to the permeability evolution model of the porous matrix established in this study. Besides, the influence mechanisms of moisture on fitting coefficients in the function were analyzed. (2) The permeability decreases with the increase of in-situ stress (e.g., confining pressure or volumetric stress) in a negative exponential manner. (3) The curves of permeability variations with moisture content are not always linear, and the permeability is more sensitive to the moisture content than the volumetric stress in the test range. Moreover, the sensitivity of permeability varies in different regions. These results would be beneficial for permeability prediction and surface well parameters design.
\end{abstract}

\section{Introduction}

Coalbed methane $(\mathrm{CBM})$ is an abundant valuable resource in underground coal mines. It is estimated that China bears approximately 36.8 trillion $\mathrm{m}^{3}$ of CBM in its reservoirs shallower than $2 \mathrm{~km}$, ranking the third country in the world [1]. Qinshui Basin whose CBM reserve accounts for $1.08 \%$ of the total CBM reserve in China is one of the largest CBM reservoirs [2]. However, the reservoir is generally characterized by low permeability, which seriously inhibits efficient CBM extraction [3]. In-situ surface well extraction is a technique for enhancing the permeability and relieving the pressure of coal seams. Permeability is a key parameter for surface well design, and its temporal and spatial variations remarkably affect the occurrence state, migration, and extraction of CBM [4]. Scholars have conducted extensive researches on the factors influencing permeability, including in-situ stress field [5], gas pressure [6], Klinkenberg effect [7], geothermal field [8], geoelectric field [9], acoustic field [10], and physical properties [11]. These findings have allowed the mechanics of permeability evolution to be deliberated and also provided an adequate data volume and dimension for machine learning which has been proven to be a powerful tool for permeability prediction $[12,13]$. Specifically, the process of fracturing, drainage, and gas extraction in surface wells destroys the original stress distribution balance and results in the existence of stress concentration or relief region [14]. Besides, the large amount of fracturing fluids leads to 
TABle 1: Proximate analysis results and adsorption constants of coal samples.

\begin{tabular}{lcccccc}
\hline \multicolumn{3}{c}{ Proximate analysis } & Ture density $\left(\mathrm{t} / \mathrm{m}^{3}\right)$ & Bulk density $\left(\mathrm{t} / \mathrm{m}^{3}\right)$ & Porosity (\%) & $\begin{array}{c}\text { Absorption constant } \\
a\left(\mathrm{~cm}^{3} / \mathrm{g}_{\text {daf }}\right)\end{array}$ \\
$M_{a d}(\%)$ & $A_{a d}(\%)$ & $V_{d a f}(\%)$ & $\left.\mathrm{MPa}^{-1}\right)$ \\
\hline 0.49 & 10.31 & 16.01 & 1.46 & 1.43 & 2.05 & 34.14 \\
\hline
\end{tabular}

regional differences in water-bearing conditions. Therefore, special attention needs to be paid to in-situ stress and moisture content of coal seam for the sake of permeability evolution investigation and prediction, gas flow simulation around the wells, and parameter design of CBM surface wells.

The development of uniaxial and triaxial loading devices has actively promoted the knowledge of permeability evolution characteristics under different stress conditions [15, 16]. The permeability-strain curve of coal corresponds well to its full stress-strain curve. To be specific, the permeability drops first and then rises as a coal sample gets loaded, deformed, and destructed [5]. The peak value of coal permeability lags behind that of stress and strain, suggesting that the characteristics of CBM flow are closely related to the evolution of coal damage generated in the loading process. In addition, scholars have carried out abundant researches on seepage tests under complex loading/unloading paths and loading/unloading rates and on the establishment of permeability models in the case of multifield coupling [17], but these researches are mostly focused on dry coal. The permeability evolution of water-bearing coal in the case of moisture-stress coupling is rarely reported.

The influence of moisture on the permeability of CBM reservoirs is primarily reflected in coal deformation, gas desorption, and migration [18]. Pan et al. [19] believed that moisture in the coal matrix would cause coal swelling/shrinkage and mechanical property alteration that would impact on coal permeability under reservoir conditions. Zhao et al. [20] and Gai et al. [21] investigated the desorption law of coal subjected to high-pressure water injection and made a comparison with the natural desorption state. Guo and $\mathrm{Su}$ [22] conducted laboratory tests on the starting pressure gradient and permeability under different water saturation conditions. The test results showed that the permeability gradually declined and the starting pressure gradient gradually rose with the increase of water saturation degree. Nie et al. [23] explored the microscopic mechanism of gas adsorption on coal samples with different moisture contents in light of molecular thermodynamics and surface physicochemical theories. Wang et al. [24] probed into the relationship among moisture content, porosity, and permeability of fractured coal. Yin et al. [25], Liu et al. [26], Wei et al. [27], and Yuan and Jiang [28] analysed the seepage characteristics of gasbearing coal with different moisture contents and found that the moisture content and permeability shared a linear negative relationship or negative exponential variation law. Hao et al. [29] performed axial and radial gas seepage experiments and revealed that the axial and radial permeabilities of coal first increased and then decreased with the rise of moisture content. Nevertheless, these researches failed to achieve a unified understanding, and the varied research results imply the difficulty in clearly explaining the effect of coupling terms on gas adsorption, diffusion, and seepage.

This study is focused on investigating the permeability evolution of gas-saturated raw coal samples with different moisture contents under varying stresses. Firstly, the experimental conditions were simplified by setting constant temperature and gas pressure, unidirectional loading path, and resaturated adsorption after the break of balance, so as to avoid irrelevant factors. Then, the relationship between effective stress and permeability was described by a new function that has a clear physical meaning based on the established permeability evolution model of the porous matrix. Furthermore, the mutual effect of moisture content and volumetric stress on permeability were obtained, and conclusions different from the abovementioned ones were drawn. Finally, a sensitivity analysis was performed in the test region.

\section{Materials and Methods}

2.1. Engineering Background. Yuwu Coal Mine is located in the south of Qinshui Basin, China. The buried depth of S2107 working face of the mine lies in the range of 480$543 \mathrm{~m}$. No. 3 coal seam that is being mined belongs to a high-gas and low-permeability coal seam with a gas content of $7.71 \mathrm{~m}^{3} / \mathrm{t}$, a gas emission initial volume from a 100 meter-long borehole of $1.42 \mathrm{~m}^{3} / \mathrm{min} \cdot \mathrm{h}$, and a permeability coefficient of $0.28-0.42 \mathrm{~m}^{2} /\left(\mathrm{MPa}^{2} \cdot \mathrm{d}\right)$. The proximate analysis results and adsorption constants of coal samples from the No. 3 coal seam are listed in Table 1 .

Surface wells \#1-52 and \#1-54 were constructed for conducting permeability-enhancing fracturing on S2107 working face before gas extraction. No. 1-No. 12 gas extraction drilling sites were arranged along the tailentry, and the single-hole gas flow rate was recorded within $50 \mathrm{~d}$. During this period, the drilling sites were not affected by mining activities. The analysis results show that the influence radii of surface wells \#1-52 and \#1-54 are 85-100 m and 39-42 m, respectively. Coal samples YW1-YW4 were taken from the affected zone in Figure 1.

2.2. Coal Sample Preparation. The steps of coal sample preparation are shown in Figure 2. (1) Standard raw coal samples with the size of $\phi 50 *(100 \pm 2) \mathrm{mm}$ were prepared with the aid of a wire cutting machine (Figure 2(a)), and relative homogeneity of the samples was ensured through density measurement and wave velocity measurement (PDS-SW ultrasonic detector). Samples YW1-YW3 almost bear no cracks (wave velocity range $1921.8-2050.8 \mathrm{~m} / \mathrm{s}$ ), while Sample YW4 owns obvious cracks on its surface (wave velocity range 1826.8$2033.8 \mathrm{~m} / \mathrm{s}$ ). (2) Preparation of coal samples with different moisture contents $\Phi$ : YW1 $(\Phi=1.98 \%)$, the samples that 


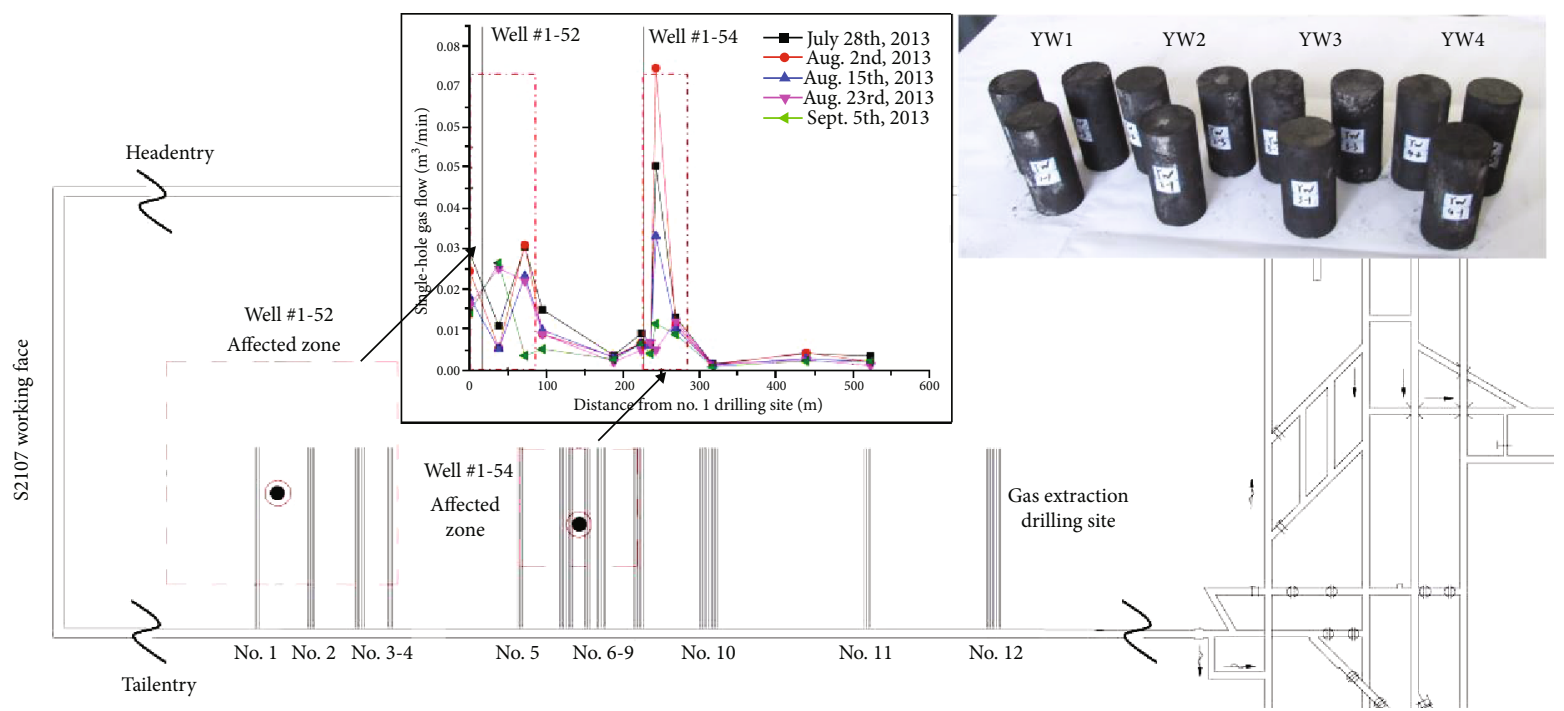

FIgURE 1: Affected zone of surface wells where samples were taken.

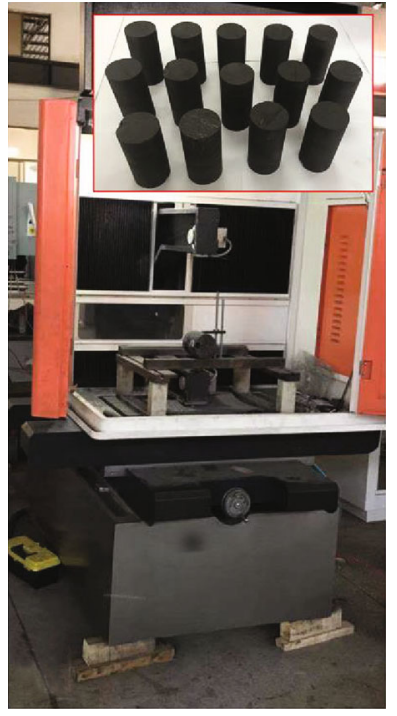

(a)

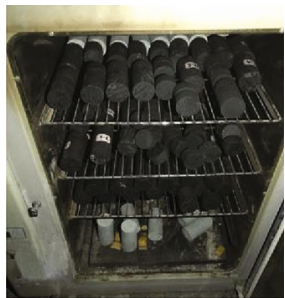

(b)

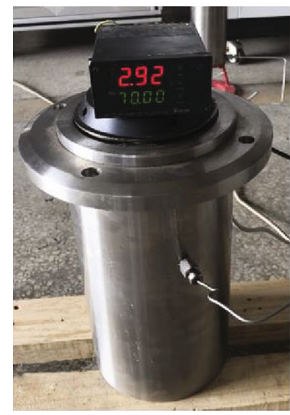

(c)

Figure 2: Coal sample preparation: (a) wire cutting; (b) drying oven; (c) pressure container.

had experienced hydraulic measures, did not receive any treatment; YW2 $(\Phi=0.22 \%)$, the samples with an ultra-low moisture content (lower than the original moisture content $0.49 \%$ ), were prepared by controlling the drying time of drying oven (Figure 2(b)); YW3 ( $\Phi=3.24 \%$ ), the samples with a high moisture content, were prepared by controlling the pressure holding time of pressure container (Figure 2(c)); YW4 $(\Phi=4 \%)$ were the crack-containing sample with a high moisture content.

2.3. Testing Apparatus. The testing apparatus is mainly composed of a loading frame, a servo hydraulic station, an air path system, a triaxial chamber, a constant-temperature oil bath, and a data acquisition system. The schematic diagram of the apparatus is displayed in Figure 3. The main technical parameters are as follows: axial stress range $10-800 \mathrm{KN}$, confining pressure range $0-15 \mathrm{MPa}$, gas pressure range $0-15 \mathrm{MPa}$, and temperature range from room temperature to $260^{\circ} \mathrm{C}$. The chamber equipped with a temperature sensor $\left(\mathrm{PT} 100, \pm 0.01^{\circ} \mathrm{C}\right.$ ) and a circumferential extensometer (Epsilon 3544 , made in USA) was placed in the constant-temperature oil bath for maintaining a constant temperature.

2.4. Experimental Contents and Procedures. The experimental conditions were simplified by setting constant temperature and gas pressure. The temperature was maintained at $20^{\circ} \mathrm{C}$. In the process of gas pressure determination, the Klinkenberg effect needs to be avoided, because a small gas pressure difference can cause gas slippage. More specifically, the Klinkenberg effect refers to the slip phenomenon that the gas flow velocity at the wall does not equal zero when the average molecular free path of gas approximates the pore size 


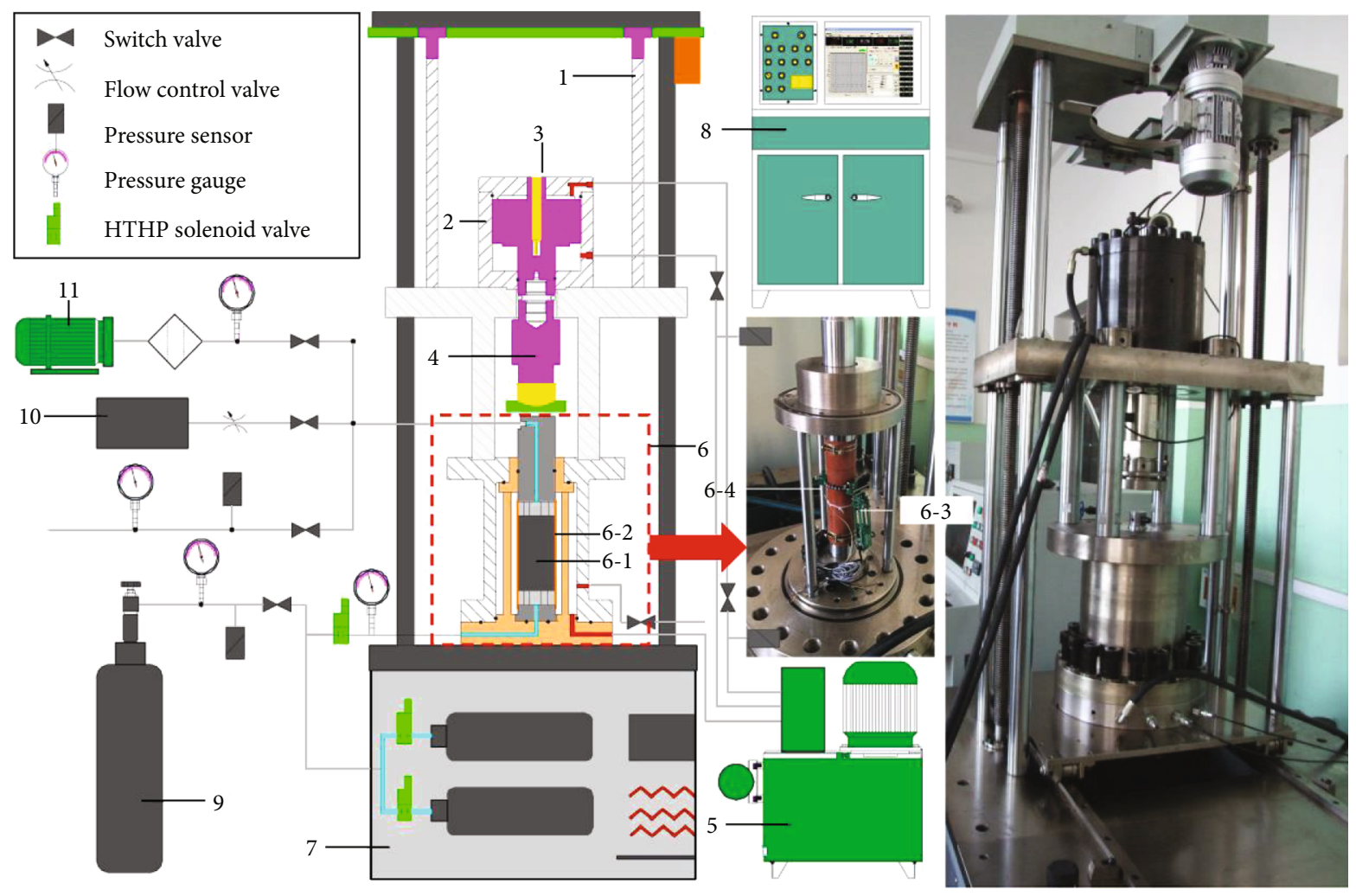

FIgURE 3: Schematic diagram of the testing apparatus. 1. Loading frame; 2. Axial loading hydro-cylinder; 3. Displacement sensor; 4. Stress sensor; 5. Servo hydraulic station; 6. Triaxial compression chamber; 6-1. Coal sample; 6-2. Heat shrinkable tube; 6-3. Circumferential extensometer; 6-4. Temperature sensor; 7. Constant-temperature oil bath; 8. Data acquisition system; 9. Gas cylinder; 10. Gas mass flow meter; 11. Vacuum pump;

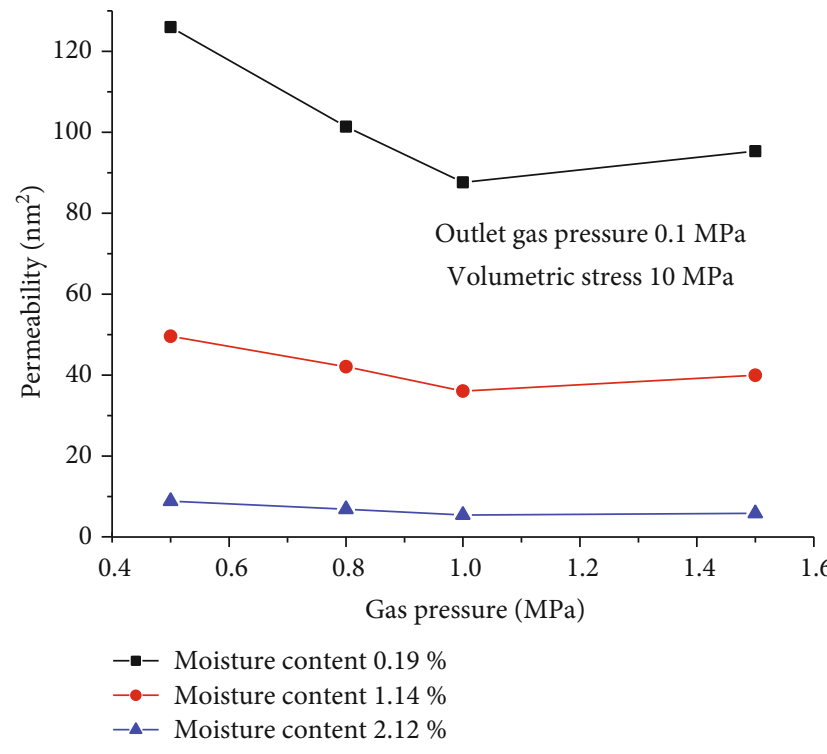

(a)

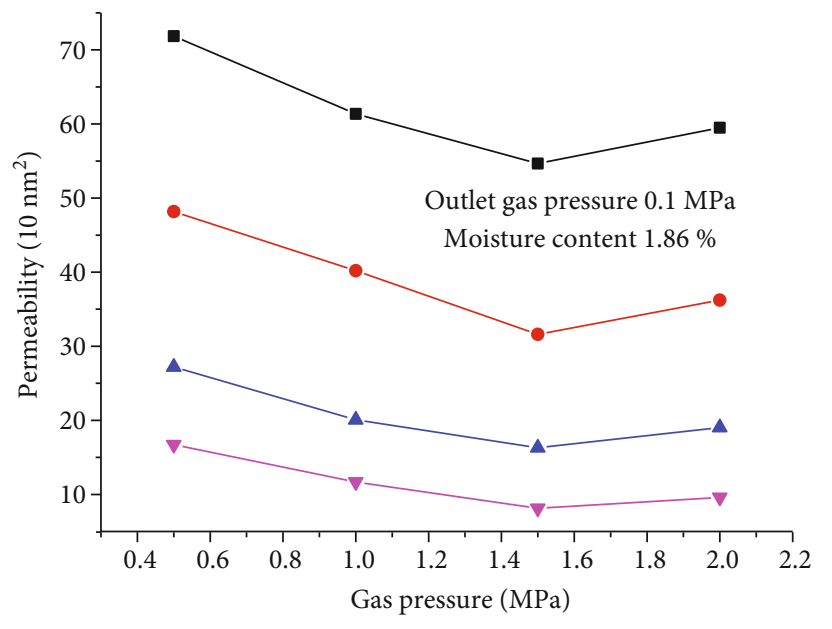

-- Volumetric stress $9 \mathrm{MPa} \quad-\boldsymbol{-}-$ Volumetric stress $21 \mathrm{MPa}$

$-\bullet$ Volumetric stress $15 \mathrm{MPa} \quad-\nabla-$ Volumetric stress $27 \mathrm{MPa}$

(b)

FIGURE 4: Influence of gas pressure on raw coal permeability: (a) Guandi Coal Mine in Qinshui Coalfield; (b) Malan Coal Mine in Qinshui Coalfield.

of a porous medium. It is manifested in varying ways under different effective stresses [5, 6, 30, 31], moisture contents $[27,28,32]$, and temperatures $[33,34]$. In view of this fact, the permeabilities of coal samples from Qinshui coalfield were tested at $20^{\circ} \mathrm{C}$ under variable gas pressures. As presented in Figure 4, the Klinkenberg effect disappears when 


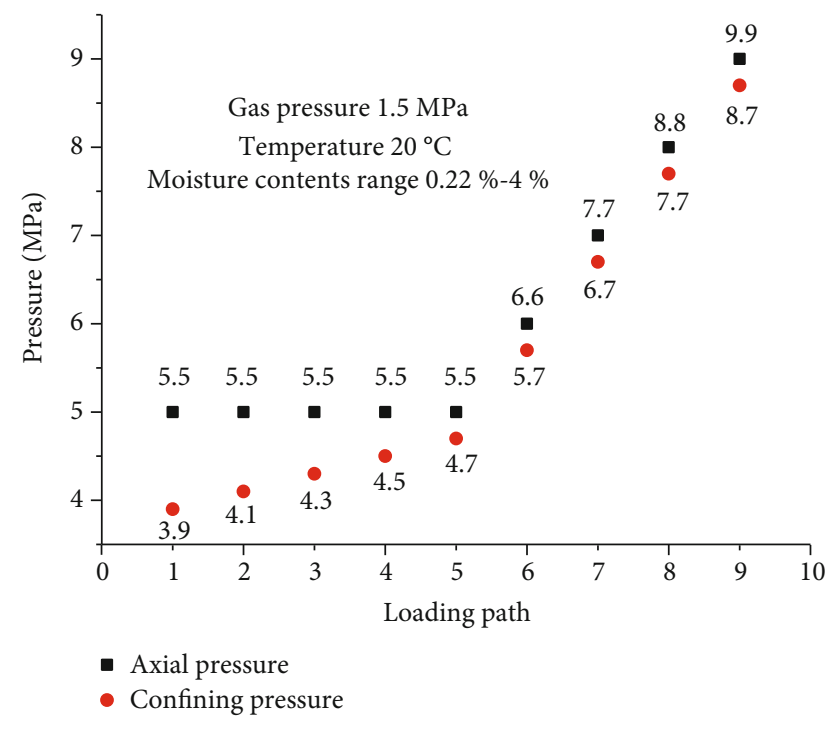

Figure 5: The loading path of the prepared samples with different moisture contents.

the gas pressure exceeds 1.0-1.5 $\mathrm{MPa}$, and its influence on the permeability becomes weaker with the rise of moisture content or volumetric stress.

Therefore, considering the in-situ stress value of No. 3 coal seam and the test results of Klinkenberg effect inflection point, the volumetric stress range and gas pressure were set as 9-27 $\mathrm{MPa}$ and 1.5 $\mathrm{MPa}$, respectively, in this experiment. The prepared samples with different moisture contents were loaded in accordance with the path in Figure 5, which can ensure that the axial pressure is higher than the confining pressure and the applied unidirectional external stress is lower than the peak strength. Gas pressure at the outlet was $0.1 \mathrm{MPa}$. Saturated adsorption treatment was conducted on the samples when the stress condition was altered, in order to prevent the adsorption/desorption process from entangling the result analysis.

Experimental procedures: (1) Sample installation: First, the side of the sample was coated with 704 silicone rubber. Then, the sample was wrapped in a heat-shrinkable tube and placed in the chamber. Afterwards, the chamber was put in the $20^{\circ} \mathrm{C}$ oil bath. (2) Initial adsorption and seepage test: The in-situ stress was raised to the initial value, and $1.5 \mathrm{MPa}$ of $\mathrm{CH}_{4}$ was injected. Next, the outlet valve was closed to allow the sample to adsorb $\mathrm{CH}_{4}$ until the equilibrium state was reached, i.e., until gas pressure in the chamber ceased changing. Finally, the outlet value was opened to record the steady flowrate. (3) The sample was allowed to readsorb $\mathrm{CH}_{4}$ for $2 \mathrm{~h}$ under an altered stress, after which the steady flowrate was recorded. Step (3) was repeated along the loading path. (4) Steps (1)-(3) were repeated for another sample.

\section{Permeability of Coal Samples: Theoretical Backgrounds}

3.1. Calculation Method for Permeability. According to the theory of geotechnical mechanics, the mean effective stress (MES) can be calculated by Eq. (1) $[35,36]$ :

$$
\sigma_{0}=\frac{1}{3}\left(\sigma_{1}+2 \sigma_{2}\right)-\frac{1}{2}\left(P_{1}+P_{2}\right)
$$

where $\sigma_{0}$ is the MES, MPa; $\sigma_{1}$ is the axial stress, $\mathrm{MPa} ; \sigma_{2}$ is the confining pressure, $\mathrm{MPa} ; P_{1}$ is the gas pressure at the inlet, $\mathrm{MPa} ; \mathrm{P}_{2}$ is the gas pressure at the outlet, $\mathrm{MPa}$, and it takes the value $0.1 \mathrm{MPa}$.

Regardless of the starting pressure gradient, the permeability of the coal sample is calculated by Eq. (2) according to Darcy's law $[37,38]$ :

$$
K=\frac{2 Q P_{a} \mu L}{A\left(P_{1}^{2}-P_{2}^{2}\right)},
$$

where $K$ is the permeability of coal sample, $10^{-3} \mu \mathrm{m}^{2}$; $Q$ is the gas flow rate at the outlet, $\mathrm{cm}^{3} / \mathrm{s} ; P_{a}$ is the atmospheric pressure, $0.1 \mathrm{MPa} ; \mu$ is the dynamic viscosity coefficient of gas, $\mathrm{Pa} \bullet$; $L$ is the length of deformed coal sample, $\mathrm{cm} ; A$ is the area of deformed coal sample, $\mathrm{cm}^{2} ; P_{1}$ is the gas pressure at the inlet, $\mathrm{Pa}$.

$$
\begin{aligned}
& L=L^{\prime}-l_{1}, \\
& A=\frac{1}{4} \pi\left(d+\frac{l_{2}}{\pi}\right)^{2},
\end{aligned}
$$

where $L$ and $A$ are the length and area of deformed coal sample; $L$ ' and $d$ are the original height and diameter of coal sample, $\mathrm{mm} ; l_{1}$ is the axial deformation of coal sample after the force loading, $\mathrm{mm} ; l_{2}$ is the radial deformation of coal sample after the force loading, $\mathrm{mm}$.

3.2. Permeability Evolution Model of Porous Matrix. The Warren-Root model of coal is presented in Figure 6 [39]. The porous matrix, which comprises pore clusters supported by skeletons, is the main gas storage space of coal (Figure 6(a)), while cracks, which completely separate the matrix, are the primary gas migration channel [40]. Figure 6(b) shows the seepage model of pores, in which the matrix is equivalent to parallel capillary tubes with equal diameter and skeletons.

Space of cracks or pores will be significantly reduced if deformation or stagnant water exists. Effective porosity is not only a key indicator for measuring the size of the space, but also an important factor that determines the adsorption/desorption and permeability of coal. The effective porosity of coal is related to its structural deformation and bulk deformation. Structural deformation refers to compression deformation of the skeleton caused by external stress, or the relative dislocation between tubes which make the tubes more closely arranged. It is usually unrecoverable. Bulk deformation refers to tube expansion caused by thermal stress or adsorption swelling, or compression deformation of tubes under the action of gas pressure [41]. Such elastic deformation caused by internal stress can be recovered.

In this study, the permeability evolution model of porous matrix considering moisture is established because Samples YW1-YW3 contain few cracks. Since the matrix will undergo 


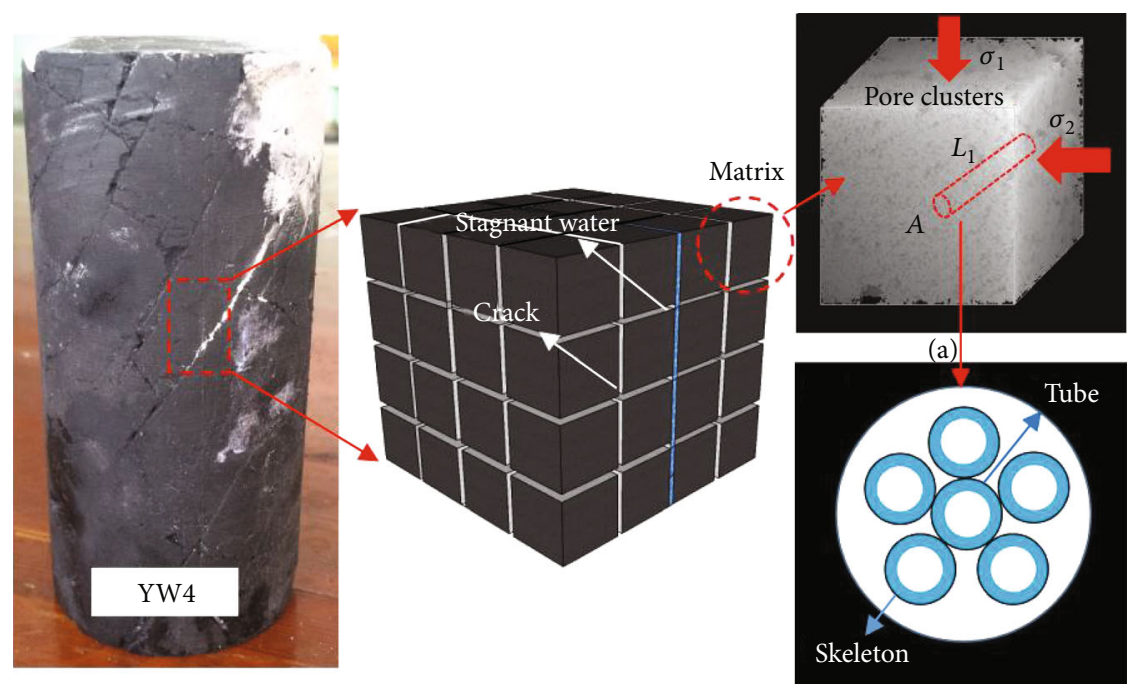

(b)

FIgURE 6: The Warren-Root model of coal: (a) pore clusters in porous matrix; (b) seepage model of pores comprising capillary tubes and skeletons.

structural deformation (external stress compression) and bulk deformation (adsorption swelling and gas pressure extrusion) under the condition of constant temperature and gas pressure, the dynamic evolution model of porosity $\varphi_{d}$ of the dry matrix is $[14,41-44]$ :

$$
\begin{aligned}
\varphi_{d} & =1-\frac{1-\varphi_{0}}{1+e}\left(1+\frac{\varepsilon_{p}}{1-\varphi_{0}}-K_{Y} \Delta P_{1}\right) \\
& =\frac{\varphi_{0}+e-\varepsilon_{p}+K_{Y} \Delta P_{1}\left(1-\varphi_{0}\right)}{1+e}
\end{aligned}
$$

where $\varphi_{d}$ is the porosity of dry matrix, $\% ; \varphi_{0}$ is the initial porosity of matrix, \%; $e$ is the volumetric strain, of which the value is negative under compression; $\varepsilon_{p}$ is the adsorption expansion strain per unit volume of coal; $K_{Y}$ is the volumetric compression coefficient, $\mathrm{MPa}^{-1}$.

The $A * L_{1}$ unit in the matrix is taken and regarded to be equivalent to the capillary tubes (Figure 6(b)). Given the fact that water distributed in macropores (pore diameter $>1 \mu \mathrm{m}$ ) and mesopores (pore diameter $=0.1-1 \mu \mathrm{m}$ ) occupies the space, the porosity of the water-containing matrix is [14]:

$$
\varphi_{w}=\varphi_{d}\left(1-\frac{\rho_{s} w}{n \rho_{w} \pi r^{2}}\right)
$$

where $\rho_{s}$ is the density of matrix, $\mathrm{kg} / \mathrm{m}^{3} ; w$ is the moisture content of matrix pores; $n$ is the number of capillary tubes per unit area $A$, tubes $/ \mathrm{m}^{2} ; \rho_{w}$ is the density of water in capillary tubes, $\mathrm{kg} / \mathrm{m}^{3}$; and $r$ is the radius of a tube, $\mathrm{m}$.

By integrating Eq. (5) with Eq. (6), the effective porosity evolution model of water-containing matrix can be obtained:

$$
\varphi_{w}=\left(1-\frac{\rho_{s} w}{n \rho_{w} \pi r^{2}}\right)\left(\frac{\varphi_{0}+e-\varepsilon_{p}+K_{Y} \Delta P_{1}\left(1-\varphi_{0}\right)}{1+e}\right),
$$

The relationship between permeability and porosity is given in the Kozeny-Carman equation established on the basis of the capillary tubes model [44]. Ignoring the change in the total surface area of coal particles per unit volume, a permeability evolution model that takes into account the moisture content in pores can be obtained:

$$
K=\frac{K_{0}}{1+e}\left(1+\frac{e-\varepsilon_{p}+K_{Y} \Delta P_{1}\left(1-\varphi_{0}\right)}{\varphi_{0}}\right)^{3}\left(1-\frac{\rho_{s} w}{n \rho_{w} \pi r^{2}}\right)
$$

where $K_{0}$ is the initial permeability of coal sample, $10^{-3} \mu \mathrm{m}^{2}$.

\section{Results and Discussion}

4.1. Effect of Mean Effective Stress on Permeability. Changes in flow rates $Q$ and permeabilities $K$ of coal samples with moisture contents of $0.22 \%, 1.98 \%$, and $3.24 \%$ under mean effective stress (MES) values of 4.2-8.3 MPa are disclosed in Figures $7(\mathrm{a})-7(\mathrm{c})$. The flow rates of coal samples decrease nonlinearly at a reduced rate with the increase of MES, and the relationship between flow rate and MES can be expressed by a quadratic function $Q=a_{1} \sigma_{0}^{2}+b_{1} \sigma_{0}+c_{1}$ where $a_{1}, b_{1}$, and $c_{1}$ are fitting coefficients.

The permeabilities and flow rates of samples with different moisture contents vary in similar trends (Figure $7(\mathrm{~d})$ ). The variation trend of permeability with MES can fitted by the power function $K=a \bullet\left(1+b \sigma_{0}\right)^{3} /\left(1+c \sigma_{0}\right)$ which agrees with the form of Eq. (8). In the function, $a, b$, and $c$ are the fitting coefficients with clear physical meanings (see Table 2 for their values), and the influence mechanisms of moisture on the values of $a, b$, and $c$ differ.

The fitting coefficient $a$ is related to the initial permeability of the matrix with specified moisture content. The value of a drops sharply with the rise of moisture content, and the effect of water on the value of $a$ is mainly reflected in the 


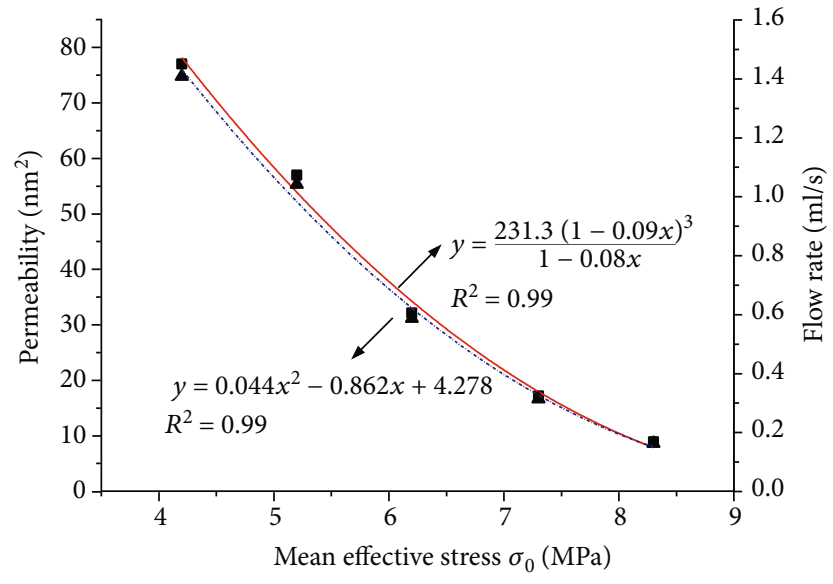

- Permeability $K_{1}$ Fitting curve of $K_{1}-\sigma_{0} \ldots \ldots$.... Fitting curve of $Q_{1}-\sigma_{0}$

(a)

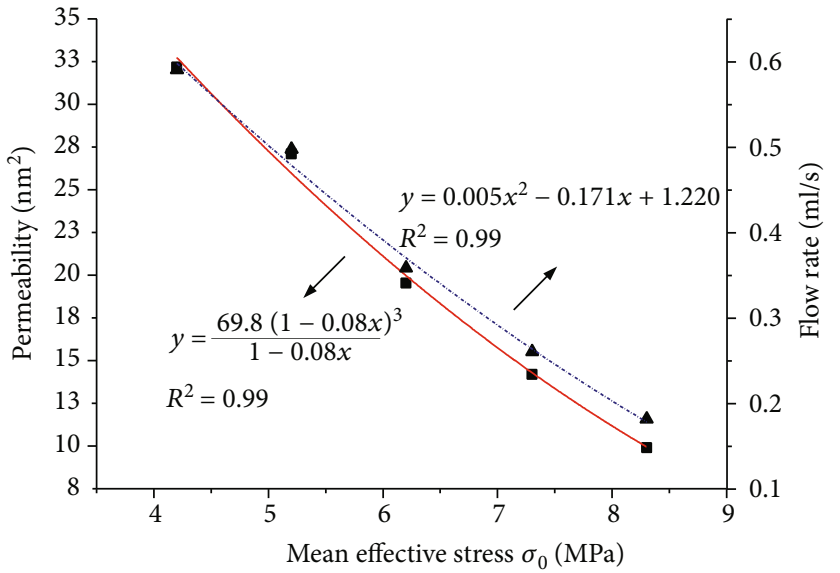

- Permeability $K_{2}$ Fitting curve of $K_{2}-\sigma_{0} \quad \ldots-\ldots . \cdots$ Fitting curve of $Q_{2}-\sigma_{0}$

(b)

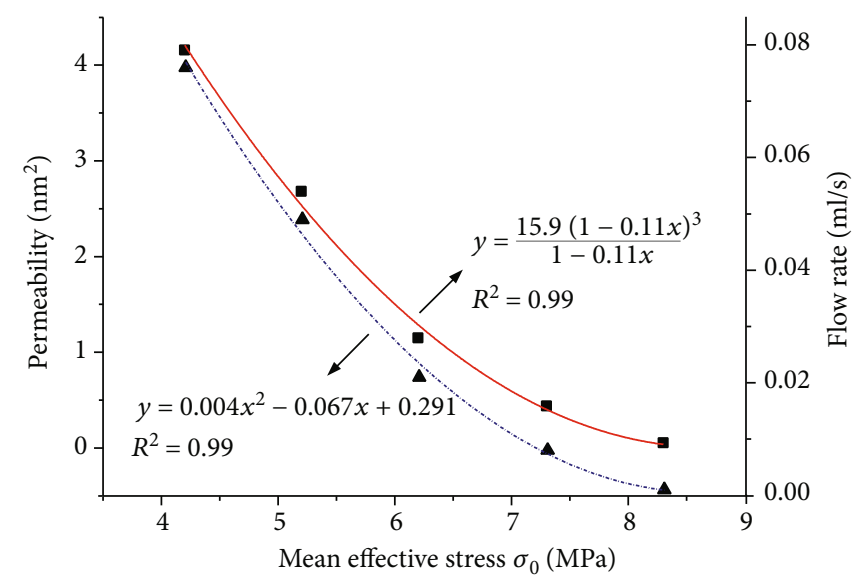

- Permeability $K_{3}$

- Flow rate $Q_{3}$

Fitting curve of $K_{3}-\sigma_{0} \quad \ldots \ldots \ldots$ Fitting curve of $Q_{3}-\sigma_{0}$

(c)

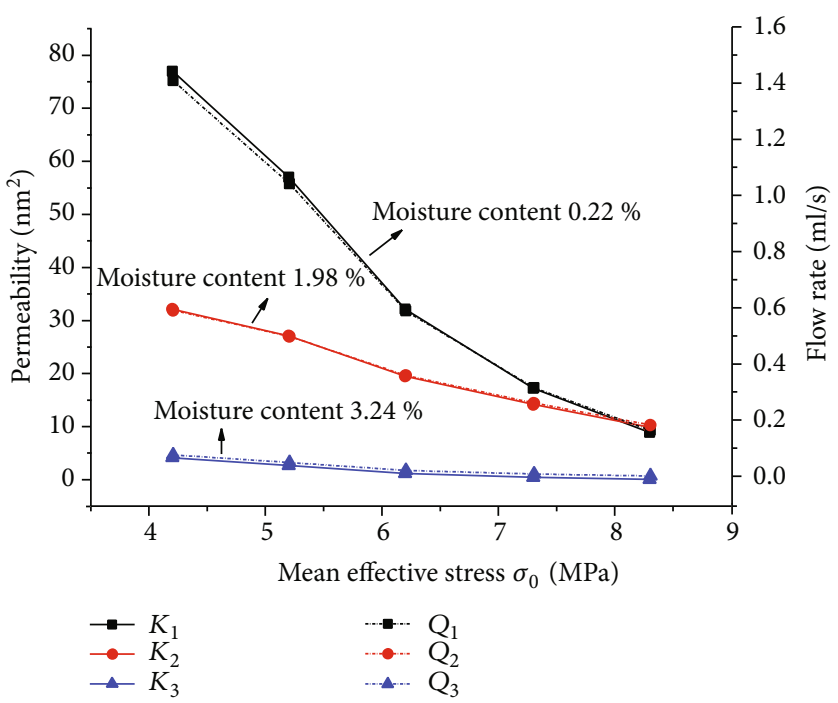

(d)

FiguRE 7: $K-\sigma_{0}$ and $Q-\sigma_{0}$ curves of samples with different moisture contents: (a) moisture content $0.22 \%$; (b) moisture content $1.98 \%$; (c) moisture content $3.24 \%$; (d) total trend. 
TABLE 2: Fitting coefficients of $K-\sigma_{0}$ curves.

\begin{tabular}{lcccc}
\hline $\begin{array}{l}\text { Value } \\
\Phi\end{array}$ & $a$ & $b$ & $c$ & $R^{2}$ \\
\hline $0.22 \%$ & 231.3 & -0.09 & -0.08 & 0.99 \\
$1.98 \%$ & 69.8 & -0.08 & -0.08 & 0.99 \\
$3.24 \%$ & 15.9 & -0.11 & -0.11 & 0.99 \\
\hline
\end{tabular}

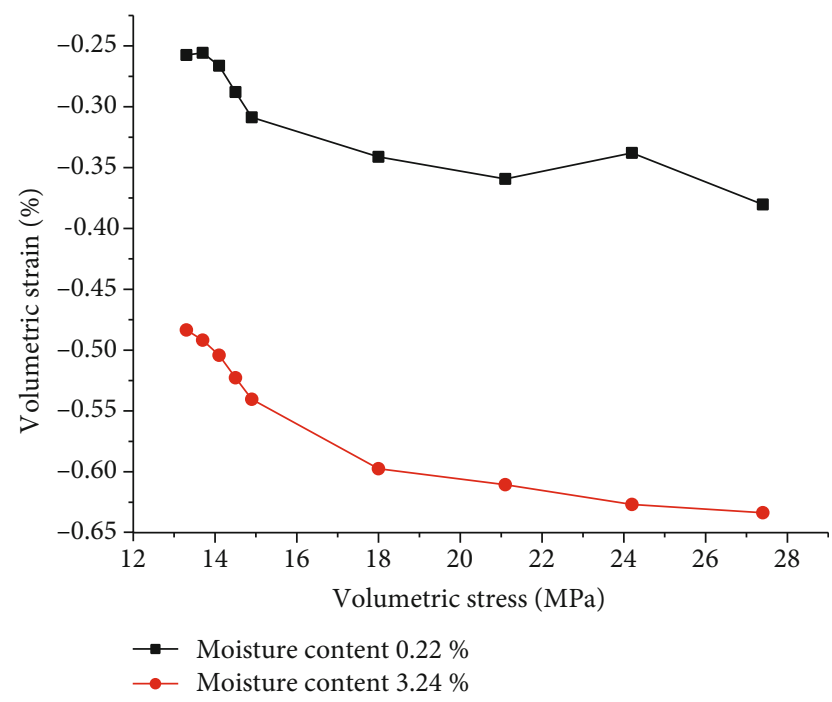

Figure 8: Volumetric stress $\Theta$-strain $e$ curves of samples with different moisture contents.

following two nondeformation aspects of matrix: (1) Free water, adhered water, and film water in macropores and mesopores occupy the gas flow channel, thus lowering the effective porosity of coal. In addition, a water film formed on the pore surface generates a certain vapor pressure, thus raising the viscous resistance of gas migration $[45,46]$. (2) Within the main space for $\mathrm{CH}_{4}$ adsorption and desorption, namely, micropores (0.01-0.1 um) and molecules structural pores $(<0.01 \mathrm{um})$, capillary resistance formed by water hinders gas desorption and exhibits a water-locking effect.

The fitting coefficient $b$ is related to the bulk deformation, structural deformation, and initial porosity of the coal matrix. By conducting wave velocity measurement, the initial permeabilities $\varphi_{0}$ of Samples YW1-YW3 are considered to be consistent, so the variation of $b$ value is mainly affected by structural deformation (external stress) and bulk deformation (adsorption swelling and gas pressure extrusion) of the matrix in this test. As the moisture content increases, the volumetric compressive strain $|e|$ goes up (Figure 8); the volumetric compression coefficient $K_{Y}$ grows [47]; and the adsorption expansion strain $\varepsilon_{p}$ does down $[26,42,43,48]$, because water molecules possess stronger adsorption competitiveness on the coal matrix surface compared with $\mathrm{CH}_{4}$ molecules $[49,50]$. Thereby, with the rise of moisture content, the effective adsorption sites of gas on the pore surface decrease, so does the adsorption expansion strain $\varepsilon_{p}$. As revealed by the analysis on the values of $|e|, \varepsilon_{p}, K_{Y}$, and $b$ with the change of moisture content, with the rise of moisture content, the effective porosity of matrix increases in terms of bulk deformation, but meanwhile the existence of external stress makes the structural deformation of the matrix with a high moisture content more obvious. As a result, the effective porosity is reduced because of the larger structural deformation.

The fitting coefficient $c$ is related to the structural deformation of the coal matrix caused by external stress. Figure 8 displays the curves of volumetric strain variation measured in the test. It can be seen that as the moisture content rises, the absolute value of volumetric strain increases, so does the absolute value of $c$.

4.2. Effect of In-Situ Stress on Permeability. Figure 9(a) demonstrates the permeability variations of samples with moisture contents of $0.22 \%, 1.98 \%$, and $3.24 \%$ under a constant axial pressure of $5.5 \mathrm{MPa}$ and confining pressures of 3.9, 4.1, 4.3, 4.5, and 4.7 MPa. Figure 9(b) shows the permeability variations of samples with moisture contents of $0.22 \%, 1.98 \%$, and $3.24 \%$ under volumetric stresses of $13.3-$ $27.3 \mathrm{MPa}$.

Obviously, permeability $K$ goes downward nonlinearly at a reduced rate with the increase of in-situ stress (e.g., confining pressure $\sigma_{2}$ or volumetric stress $\Theta$ ). The above downward trend can be fitted with a negative exponential function $K=a \cdot \exp (-b x)$ where $a$ and $b$ are the fitting coefficients and $a$ is related to the initial permeabilities of coal samples with different moisture contents. This finding corresponds to previous research results $[27,35,51]$. The reason can be explained as follows. The initial permeabilities of coal samples with different moisture contents differ. Specifically, the higher the moisture content is, the lower the initial permeability is. First, the stagnant water and the seal off the effect of water reduce the effective porosity of coal [29]. Second, with the increase of external stress, the structural deformation of coal brings about further shrinkage of gas seepage channel.

Sample YW4 $(\Phi=4 \%)$ contains evident microcracks (Figure 6). The test result shows that its permeability is up to $60 \%$ higher than the value in Figure 9 under the same in-situ stress condition. The result fully proves that although the moisture content seriously weakens coal permeability, cracks, as the dominant factor affecting coal permeability [52], will effectively weaken the negative impact of water on coal permeability.

\subsection{Mutual Effect of Moisture Content and Volumetric Stress on Permeability}

4.3.1. Relationship between Permeability and Moisture Content under Applied In-Situ Stress. Figure 10 exhibits the variation of permeability $K$ with the moisture content $\Phi$ and the volumetric stress $\Theta$. The $K-\Phi$ curves are not alway linear. In the whole region $(\Phi=0.22-3.24 \%)$, under low volumetric stresses $(\Theta<15 \mathrm{MPa}), K$ decreases nonlinearly with the increase of $\Phi$; as the volumetric stress grows (e.g., $\Theta$ $=18 \mathrm{MPa}$ ), it becomes linearly correlated with $\Phi$, which agrees with the conclusions of Liu et al. [26], Yin et al. [25, 53], and Yuan and Jiang [28]; under high volumetric stresses 


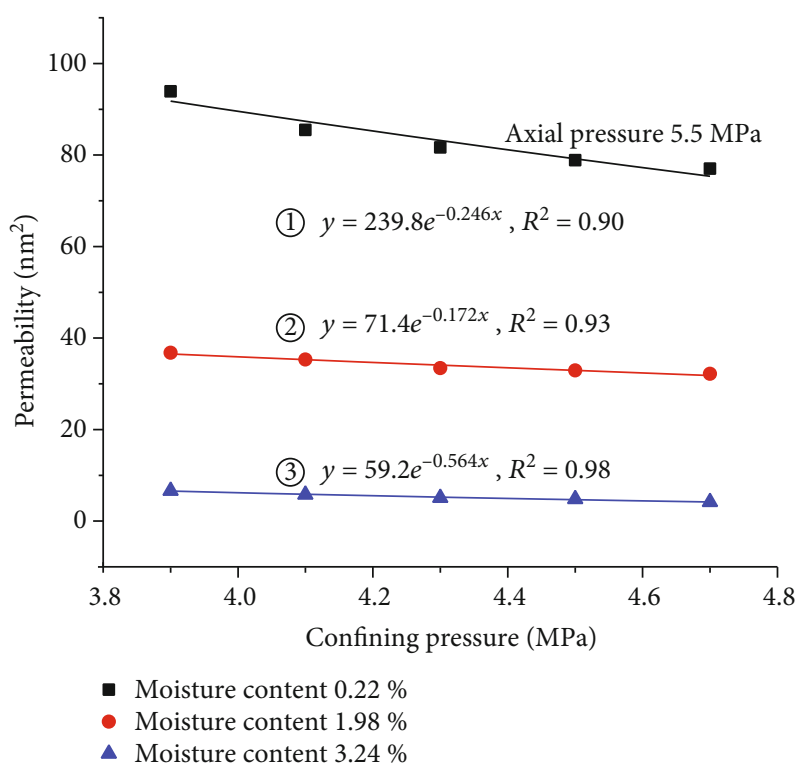

(a)

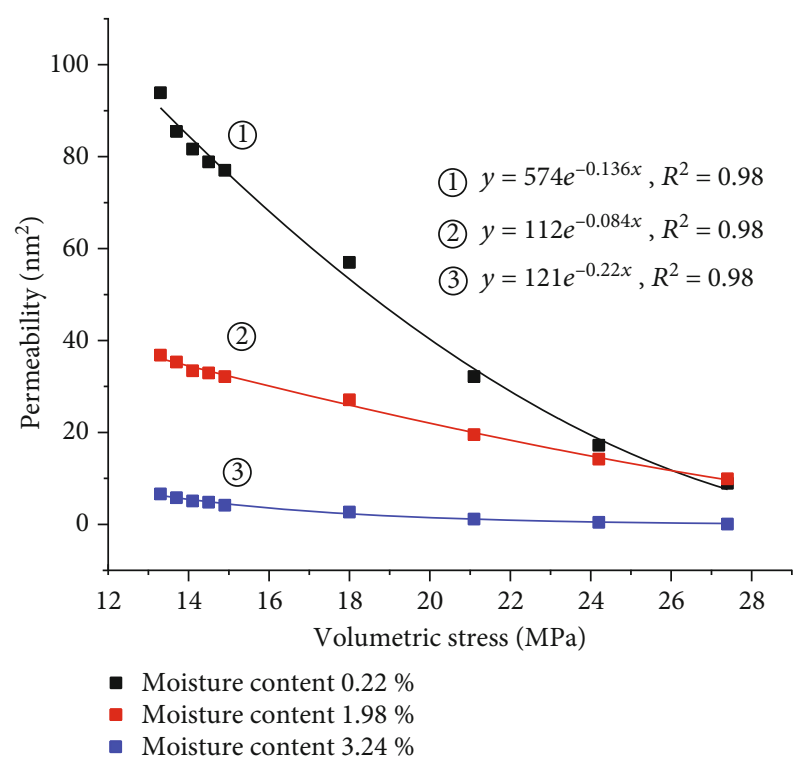

(b)

FIGURE 9: Effect of in-situ stress on permeability: (a) confining pressure; (b) volumetric stress.

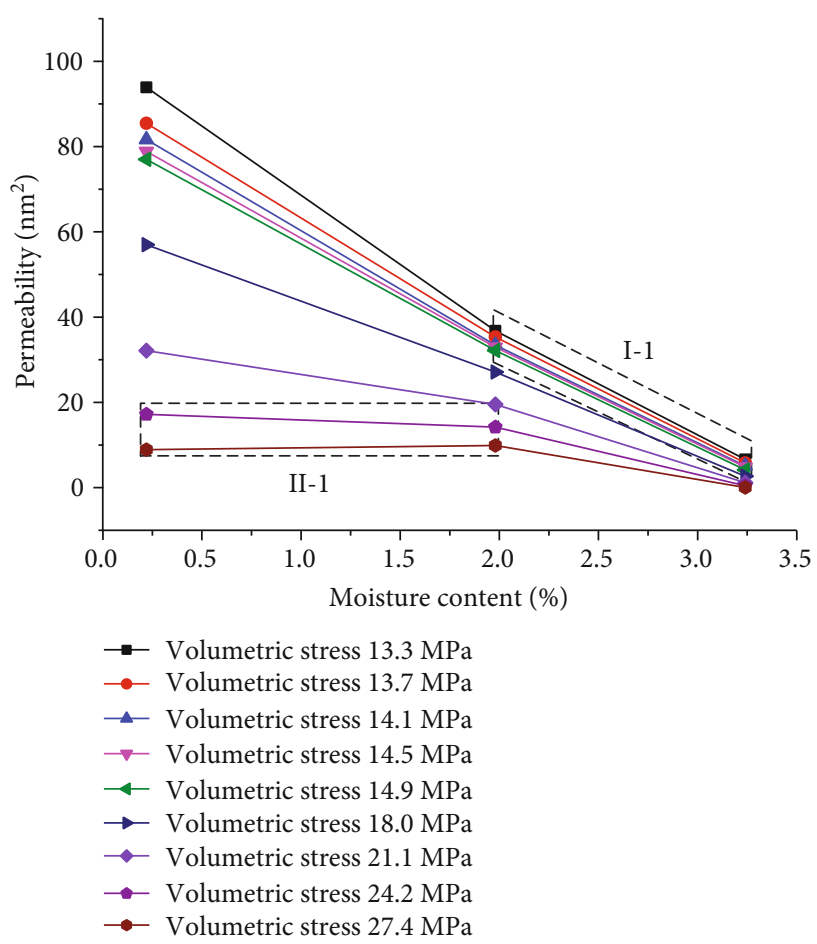

FIGURE 10: Effect of moisture content and volumetric stress on permeability.

$(\Theta>18 \mathrm{MPa})$, it is no longer linearly correlated with $\Phi$, the slope of $K-\Phi$ curve altering evidently in the vicinity of $\Phi=1.98 \%$. Moisture occupies pores and external stress causes structural deformation of the pore, both reducing the effective porosity of matrix and thus resulting in a decrease in permeability.
In different regions $(\Phi=0.22-1.98 \%$ and $\Phi=1.98-$ $3.24 \%$ ), the slope of $K-\Phi$ curve decreases with the increase of $\Theta$, because influence of $\Phi$ on $K$ weakens with the increase of $\Theta$. It is noteworthy that in Zone I- 1 where $\Phi$ is high and $\Theta$ is low, the slope of $K-\Phi$ curve remains basically constant with the increase of $\Theta$; in Zone II-1 where $\Phi$ is low and $\Theta$ is high, the slope of $K-\Phi$ curve remains basically unchanged with the increase of $\Phi$. The variation trend reflects the differences in permeability sensitivity to volumetric stress and moisture content in different regions.

4.3.2. Sensitivity Analysis of the Test Regions. To determine the influence degrees of moisture content $\Phi$ and volumetric stress $\Theta$ on permeability $K$, the sensitivity coefficients of permeability to moisture content and volumetric stress were defined as $C_{\Phi}$ and $C_{\Theta}$, respectively. The meanings of $C_{\Phi 1,2}$ and $C_{\Theta 1,2}$ were defined in the same way as above.

First, the correlation between variables was analysed. The Pearson correlation coefficient $\rho_{X, Y}$ (PPMCC) shown in Eq. (9), which is the quotient of the product of covariance and standard deviation of two variables [54], is widely used for measuring the correlation between two variables. Through calculation, the correlation between the moisture content $\Phi$ and the permeability $K$ is -0.782 (highly significant, $P<$ 0.01 ), while that between the volumetric stress $\Theta$ and the permeability $K$ is -0.470 (significant, $P<0.05$ ). In addition, $\Phi$ and $\Theta$ are two independent variables.

$$
\rho_{X, Y}=\frac{\operatorname{cov}(X, Y)}{\sigma_{X} \sigma_{Y}}=\frac{E(X Y)-E(X) E(Y)}{\sqrt{E\left(X^{2}\right)-E^{2}(X)} \sqrt{E\left(Y^{2}\right)-E^{2}(Y)}},
$$

where cov is the covariance; and $E$ is the mathematical expectation. 
TABLE 3: Calculation results of regression coefficients.

\begin{tabular}{lccccc}
\hline Coefficient & Value & Standard error & $T$ value & $P>|T|$ & Confidence interval \\
\hline$\beta_{1}$ & $-0.782(P<0.01)$ & 0.084 & -9.35 & 0 & {$[-0.95,-0.61]$} \\
$\beta_{2}$ & $-0.470(P<0.01)$ & 0.084 & -5.63 & 0 & {$[-0.64,0.30]$} \\
$\beta_{0}$ & -0.001 & 0.082 & 0 & 1 & {$[-0.17,0.17]$} \\
\hline
\end{tabular}

TABLE 4: Calculation results of regression coefficients.

\begin{tabular}{lccccc}
\hline Coefficient & Value & Standard error & $T$ value & $P>|T|$ & Confidence interval \\
\hline$\beta_{1}$ & $-52.679(P<0.01)$ & 2.120 & -24.85 & 0 & {$[-57.06,-48.29]$} \\
$\beta_{2}$ & $-6.287(P<0.01)$ & 0.250 & -25.1 & 0 & {$[-6.8,-5.77]$} \\
$\beta_{3}$ & $1.909(P<0.01)$ & 0.114 & 16.74 & 0 & {$[1.67,2.14]$} \\
$\beta_{0}$ & 175.984 & 4.655 & 37.81 & 0 & {$[166.36,185.61]$} \\
\hline
\end{tabular}

(1) Sensitivity analysis in the whole test region. Based on the correlation analysis, a multiple regression model was established to calculate the sensitivity coefficients $C_{\Phi}$ and $C_{\Theta}$. The data in Figure 10 were subjected to $Z$-Score standardization via Stata software and then substituted into the regression equation $Y_{K}=\beta_{0}+\beta_{1} X_{\Phi}+\beta_{2} X_{\Theta}+\mu_{I}$ where $\beta_{0}$, $\beta_{1}$, and $\beta_{2}$ are the regression coefficients and $\mu_{I}$ is the error term.

The permeability $K$ is more sensitive to the moisture content $\Phi$ in the whole test region. The overall sensitivity coefficients $C_{\Phi 1}=d Y_{K} / d X_{\Phi}=\beta_{1}$ and $C_{\Theta 1}=d Y_{K} / d X_{\Theta}=\beta_{2}$ were defined. Their values $C_{\Phi 1}=-0.782$ (highly significant, $P<$ 0.01 ) and $C_{\Theta 1}=-0.470$ (highly significant, $P<0.01$ ) can be found in Table 3. In the whole test region, $\left|C_{\Phi 1}\right|>\left|C_{\Theta 1}\right|$, that is, permeability is more sensitive to moisture content on the whole.

(2) Sensitivity analysis in different regions. The interaction variable [55-57] $\beta_{3} X_{\Phi} X_{\Theta}$ was added into the regression equation $Y_{K}=\beta_{0}+\beta_{1} X_{\Phi}+\beta_{2} X_{\Theta}+\beta_{3} X_{\Phi} X_{\Theta}+\mu_{2}$ for comparing the values of $C_{\Phi}$ and $C_{\Theta}$ in different regions. The regional sensitivity coefficients $C_{\Phi 2}=d Y_{K} / d x_{\Phi}=\beta_{1}+\beta_{3} *$ $X_{\Theta}$ and $C_{\Theta 2}=d Y / d x_{\Theta}=\beta_{2}+\beta_{3} * X_{\Phi}$ were defined.

As given in Table 4 , the interaction term coefficient is 1.909 (highly significant, $P<0.01$ ), suggesting that although moisture content and volumetric stress are independent variables, they exert a mutual effect on permeability. $C_{\Phi 2}=-$ $52.679+1.909 * X_{\Theta}$ and $C_{\Theta 2}=-6.287+1.909 * X_{\Phi}$ demonstrate that the sensitivity coefficient $C_{\Phi 2}$ decreases gradually with the increase of volumetric stress while $C_{\Theta 2}$ decreases gradually with the increase of moisture content (Figure 11). Therefore, the sensitivity coefficient $C_{\Phi 2}$ decreases with the increase of volumetric stress $\Theta$ so that the slope of $K-\Phi$ curve becomes smaller and smaller in the ranges of $\Phi=$ $0.22-1.98 \%$ and $\Phi=1.98-3.24 \%$ (Figure 10), which indicates the weakening influence of moisture content on permeability.

Figure $12(\mathrm{a})$ is a three-dimensional diagram of the data in Figure 10. As can be observed in Figure 12(b), $\left|C_{\Phi 2}\right|>\left|C_{\Theta 2}\right|$ in Zone $\mathrm{I}\left(X_{\Theta}<24.37+X_{\Phi}\right)$, that is, permeability is more

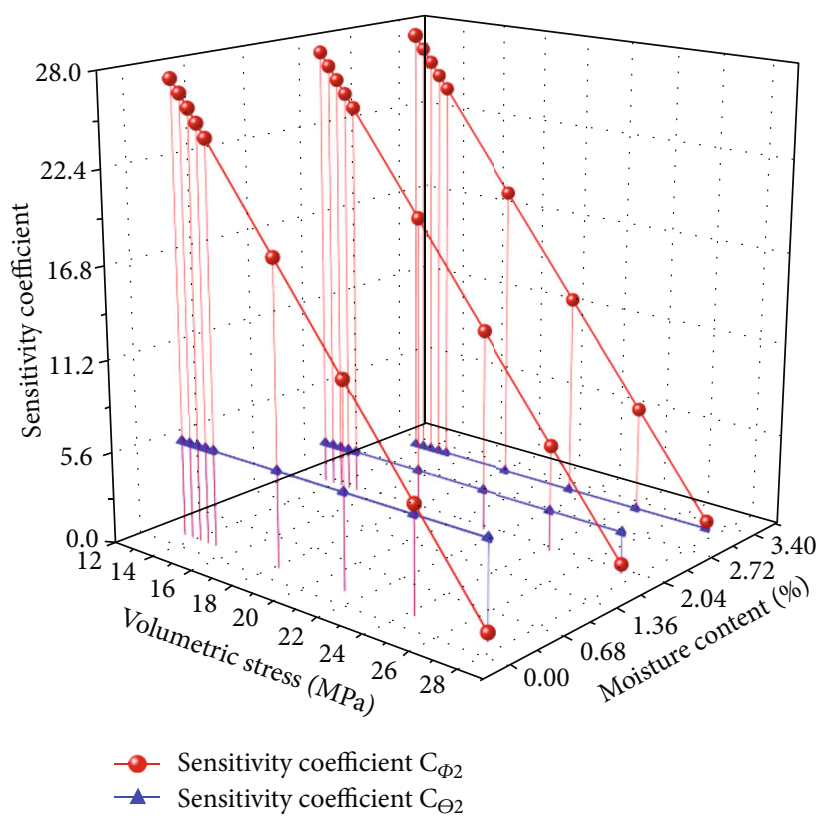

FIgURE 11: Calculation of sensitivity coefficient of each experimental condition.

sensitive to moisture content in this region; $\left|C_{\Phi 2}\right|<\left|C_{\Theta 2}\right|$ in Zone II $\left(X_{\Theta}>24.37+X_{\Phi}\right)$, that is, permeability is more sensitive to volumetric stress in the region. The constant slopes of $K-\Phi$ curves in Zone I-1 and Zone II-1 in Figure 10 indicate the absolute influence of high volumetric stress or high moisture content on permeability.

The value of $C_{\Phi 2}$ is larger than that of $C_{\Theta_{2}}$ when the volumetric stress is lower than $15 \mathrm{MPa}$ (Figure 11). At this time, coal permeability is not simply linearly correlated but shares a negative exponential relationship with moisture content (Figure 12(a)). This finding differs from the research results of Yin et al. [25, 53], probably because the briquette samples used by Yin et al. possess a homogeneous internal structure while the complex pore structure of raw coal samples used in this test decides the more complex influence mechanism 


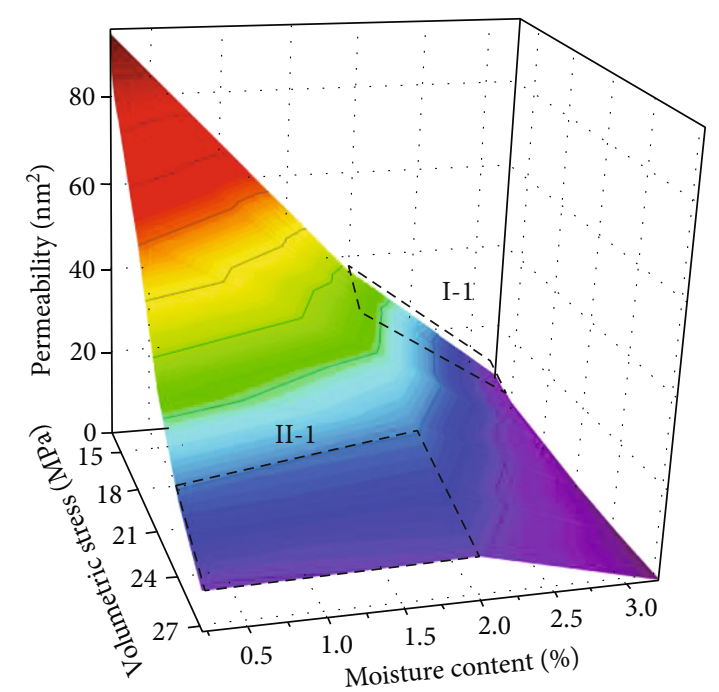

(a)

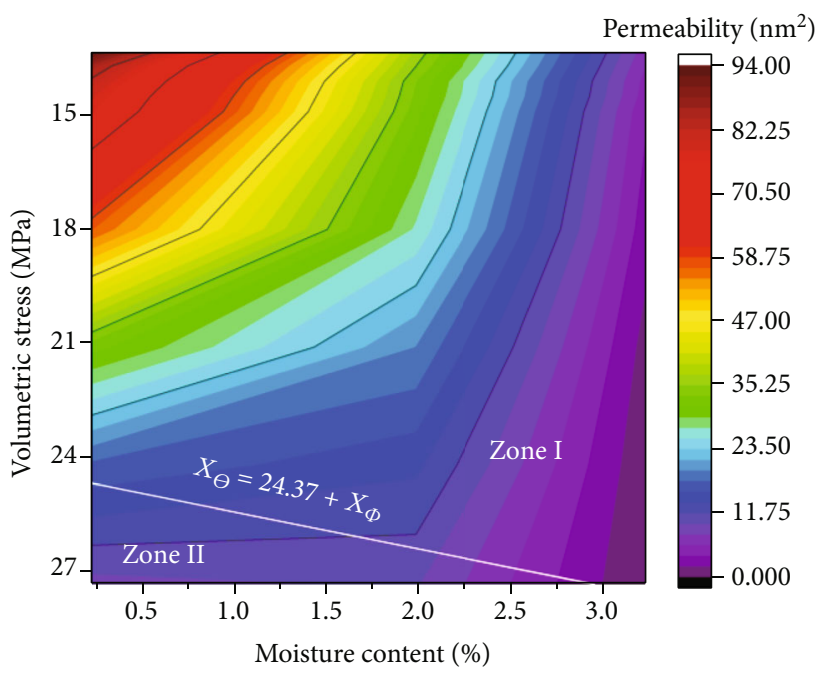

(b)

FIgURE 12: Division of sensitive regions under the test conditions: (a) Three-dimensional diagram of Figure 10; (b) Top view.

of moisture on raw coal permeability. Under a low volumetric stress, the pores in coal are slightly affected by stress, and the coal is strongly hydrophilic. As a result, the increased water adsorbs on the pore surface easily and meanwhile occupies the effective gas seepage channel. Since the porosity of coal is an important parameter affecting gas permeability, the permeability of coal falls rapidly with the rise of moisture content under a low volumetric stress. With the increase of volumetric stress, the sensitivity of permeability to moisture content decreases, so that permeability becomes linearly correlated with moisture content. After volumetric stress continues to increase to $24 \mathrm{MPa}$, the coal sample gets more sensitive to volumetric stress (Zone II in Figure 12(b)), which is reflected by the phenomenon that the increase of moisture content fails to notably lower permeability under a low moisture content.

\section{Conclusions}

In this study, a series of experiments were performed for grasping the permeability evolution of gas-saturated raw coal under the coupled influences of moisture contents and insitu stress. The main conclusions reached are as follows.

(1) A permeability evolution model of a porous matrix was established. On the basis of this mode, it is found that the power function $K=a \cdot\left(1+b \sigma_{0}\right)^{3} /\left(1+c \sigma_{0}\right)$ can be used to describe the relationship between MES $\sigma_{0}$ and permeability $K$. In this function, the fitting coefficient $a$ is related to the initial permeability with specified moisture content; $b$ is related to the bulk deformation, structural deformation, and initial porosity of coal matrix; and $c$ is related to the structural deformation of coal matrix caused by external stress. The influence mechanisms of moisture on these coefficients were analysed according to the experimental results afterwards
(2) Permeability decreases nonlinearly with the increase of in-situ stress (e.g., confining pressure $\sigma_{2}$ or volumetric stress $\Theta$ ), which can be fitted by a negative exponential function $K=a \cdot \exp (-b x)$, where $a$ is related to the initial permeabilities of coal samples with specified moisture content $\Phi$

(3) The mutual influences of moisture content and volumetric stress on permeability were analysed. In different regions, the slope of $K-\Phi$ curve decreases with the increase of $\Theta$, because the increase of $\Theta$ would weaken the influence of $\Phi$ on $K$. Overall, the $K-\Phi$ curves are not always linear. The variation reflects the differences in permeability sensitivity to volumetric stress and moisture content in different regions

\section{Data Availability}

The data used to support the findings of this study are available from the corresponding author upon request.

\section{Conflicts of Interest}

The authors declare no conflicts of interest.

\section{Acknowledgments}

The authors are grateful to Professor Yaojiang Zhao from Taiyuan University of Technology for his support and contribution in this study. This work has been supported by the Fundamental Research Funds for the Central Universities (2017XKZD06).

\section{References}

[1] H. Wang, Y. Cheng, W. Wang, and R. Xu, "Research on comprehensive CBM extraction technology and its applications in 
China's coal mines," Journal of Natural Gas Science \& Engineering, vol. 20, pp. 200-207, 2014.

[2] Z. Meng, J. Zhang, and R. Wang, "In-situ stress, pore pressure and stress-dependent permeability in the southern Qinshui Basin," International Journal of Rock Mechanics and Mining Sciences, vol. 48, no. 1, pp. 122-131, 2011.

[3] J. Fan, P. Liu, J. Li, and D. Jiang, "A coupled methane/air flow model for coal gas drainage: Model development and finitedifference solution," Process Safety and Environmental Protection, vol. 141, pp. 288-304, 2020.

[4] J. Lin, T. Ren, G. Wang, and J. Nemcik, "Simulation investigation of N2-injection enhanced gas drainage: model development and identification of critical parameters," Journal of Natural Gas Science \& Engineering, vol. 55, pp. 3041, 2018.

[5] D. Wang, R. Lv, J. Wei et al., "An experimental study of seepage properties of gas-saturated coal under different loading conditions," Energy Science \& Engineering, vol. 7, no. 3, pp. 799-808, 2019.

[6] S. Cao, P. Guo, Y. Li, and Y.-J. Bai, "Effect of gas pressure on gas seepage of outburst coal," Journal of China Coal Society, vol. 35, no. 4, pp. 595-599, 2010.

[7] K. Wang, F. Du, and G. Wang, "Investigation of gas pressure and temperature effects on the permeability and steady-state time of Chinese anthracite coal: an experimental study," Journal of Natural Gas Science and Engineering, vol. 40, pp. 179188, 2017.

[8] X. Li, X. Yan, and Y. Kang, "Effect of temperature on the permeability of gas adsorbed coal under triaxial stress conditions," Journal of Geophysics and Engineering, vol. 15, no. 2, pp. 386396, 2018.

[9] E. Wang, L. Zhang, X. He, and Z. Liu, "Electric field response of gas permeability of coal," Journal of China University of Mining \& Technology, vol. 33, no. 1, pp. 62-65, 2004.

[10] J. Yan and L. Li, "Experimental study of acoustic effects on coal gas permeability," Journal of China Coal Society, vol. 35, pp. 81-85, 2010.

[11] C. R. Clarkson and R. M. Bustin, "Variation in permeability with lithotype and maceral composition of Cretaceous coals of the Canadian Cordillera," International Journal of Coal Geology, vol. 33, no. 2, pp. 135-151, 1997.

[12] O. Sudakov, E. Burnaev, and D. Koroteev, "Driving digital rock towards machine learning: predicting permeability with gradient boosting and deep neural networks," Computers \& Geosciences, vol. 127, pp. 91-98, 2019.

[13] A. Erofeev, D. Orlov, A. Ryzhov, and D. Koroteev, "Prediction of porosity and permeability alteration based on machine learning algorithms," Transport in Porous Media, vol. 128, no. 2, pp. 677-700, 2019.

[14] Y. Zhao, S. Cao, Y. Li et al., "The occurrence state of moisture in coal and its influence model on pore seepage," RSC Advances, vol. 8, no. 10, pp. 5420-5432, 2018.

[15] Y. Li, C. A. Tang, D. Li, and C. Wu, "A new shear strength criterion of three-dimensional rock joints," Rock Mechanics and Rock Engineering, vol. 53, no. 3, pp. 1477-1483, 2019.

[16] Z. Li, S. Yu, W. Zhu et al., "Dynamic loading induced by the instability of voussoir beam structure during mining below the slope," International Journal of Rock Mechanics and Mining Sciences, vol. 132, p. 104343, 2020.

[17] D. Zhang, Y. Yang, H. Wang, X. Bai, C. Ye, and S. Li, "Experimental study on permeability characteristics of gas- containing raw coal under different stress conditions," Royal Society Open Science, vol. 5, no. 7, article 180558, 2018.

[18] A. Liu, S. Liu, X. Hou, and P. Liu, "Transient gas diffusivity evaluation and modeling for methane and helium in coal," International Journal of Heat and Mass Transfer, vol. 159, p. 120091, 2020.

[19] Z. Pan, L. D. Connell, M. Camilleri, and L. Connelly, "Effects of matrix moisture on gas diffusion and flow in coal," Fuel, vol. 89, no. 11, pp. 3207-3217, 2010.

[20] D. Zhao, Z. Feng, and Y. Zhao, "Experimental study of effects of high pressure water injection on desorption characteristic of coal-bed methane (CBM)," Chinese Journal of Rock Mechanics and Engineering, vol. 30, no. 3, pp. 547-555, 2011.

[21] N. Gal, V. Lagneau, and A. Charmoille, "Experimental characterization of $\mathrm{CH}_{4}$ release from coal at high hydrostatic pressure," International Journal of Coal Geology, vol. 96, pp. 8292, 2012.

[22] H. Guo and X. Su, "Research on the mechanism of gas emission inhibition in water-flooding coal seam," Journal of China Coal Society, vol. 35, no. 6, pp. 928-931, 2010.

[23] B. Nie, X. Liu, S. Yuan et al., "Sorption charateristics of methane among various rank coals: impact of moisture," Adsorption, vol. 22, no. 3, pp. 315-325, 2016.

[24] S. Wang, D. Elsworth, and J. Liu, "Permeability evolution in fractured coal: the roles of fracture geometry and water-content," International Journal of Coal Geology, vol. 87, no. 1, pp. 13-25, 2011.

[25] G. Yin, C. Jiang, J. Xu, S. Peng, and W. Li, "Experimental study of influences for water content in coalbed gas reservoirs on methane seepage," Chinese Journal of Rock Mechanics and Engineering, vol. 30, pp. 3401-3406, 2011.

[26] Q. Liu, L. Zhang, H. Li, and Z. Deng, "Effect of moisture content on CBM seepage," Journal of China Coal Society, vol. 39, no. 9, pp. 1840-1844, 2014.

[27] P. Wei, L. Wei, and D. Wang, "Experimental study of moisture content influences on permeability of coal containing gas," Journal of China Coal Society, vol. 39, no. 1, pp. 97-103, 2014.

[28] X. Yuan and D. Jiang, "Experimental study of gas permeability of coal under different moisture state," Journal of Mining \& Safety Engineering, vol. 35, no. 3, pp. 649-656, 2018.

[29] D. Hao, L. Zhang, Z. Ye, S. Tu, and C. Zhang, "Experimental study on the effects of the moisture content of bituminous coal on its gas seepage characteristics," Arabian Journal of Geosciences, vol. 11, no. 15, p. 436, 2018.

[30] B. Li, J. Wei, K. Wang, and Y. Jia, "Experimental study of nonlinear motion law for gas seepage in coal seams," Chinese Journal of Rock Mechanics and Engineering, vol. 33, pp. 3219-3224, 2014.

[31] G. Zhang, Y. Hu, and D. Jiang, "Study on the factors affecting gas permeability of coal," Journal of Chongqing University (Natural Science Edition), vol. 18, no. 3, pp. 27-30, 1995.

[32] F. Ma, Y. Wang, L. Wang, S. Zhang, and Q. Zhang, "Influence of moisture content in coal rock on permeability," Lithologic Reservoirs, vol. 25, no. 3, pp. 97-101, 2013.

[33] C. Zhang, Y. Zhao, and X. Zheng, "Coupled model of deformation and gas flow process with temperature and slippage effect," Journal of Hebei University of Science and Technology, vol. 36, no. 3, pp. 306-312, 2015.

[34] J. Xu, M. Zhang, S. Peng, B. Li, and X. Wu, "Experimental study of migration laws of gas during loading-unloading 
process at different temperatures," Rock and Soil Mechanics, vol. 37, no. 6, pp. 1579-1587, 2016.

[35] Y. S. Zhao, Multi-Field Coupling in Porous Media and its Engineering Response, Science press, BeiJing, 2010.

[36] K. Terzaghi, "Principles of soil mechanics, IV—settlement and consolidation of clay," Engineering News-Record, vol. 95, no. 3, pp. 874-878, 1925.

[37] A. E. Scheidegger, "The physics of flow through porous media," Soil Science, vol. 86, no. 6, p. 355, 1958.

[38] C. Wang, Y. Zang, L. Wang et al., "Interaction of cleat-matrix on coal permeability from experimental observations and numerical analysis," Geofluids, vol. 2019, Article ID 7474587, 15 pages, 2019.

[39] N. M. Dmitriev and V. M. Maksimov, "Models of flow through fractured-porous anisotropic media," Fluid Dynamics, vol. 42, no. 6, pp. 937-942, 2007.

[40] E. Ranjbar and H. Hassanzadeh, "Matrix-fracture transfer shape factor for modeling flow of a compressible fluid in dual-porosity media," Advances in Water Resources, vol. 34, no. 5, pp. 627-639, 2011.

[41] Y. Tao, J. Xu, M. Cheng, S. Li, and S. Peng, "Theoretical analysis and experimental study on permeability of gas-bearing coal," Chinese Journal of Rock Mechanics and Engineering, vol. 28, Supplementary 2, pp. 3364-3370, 2009.

[42] B. Li, J. Li, K. Yang, C. Ren, J. Xu, and M. Zhang, "Deformation and permeability model of coal and rock considering moisture content," Journal of China Coal Society, vol. 44, no. 4, pp. 1076-1083, 2019.

[43] X. Li, Y. Guo, and X. Wu, "Analysis of the relation of porosity, permeability and swelling deformation of coal," Journal of Taiyuan University of Technology, vol. 36, no. 3, pp. 264-266, 2005.

[44] Y. Tao, J. Xu, D. Liu, and Y. Liang, "Development and validation of THM coupling model of methane-containing coal," International Journal of Mining Science and Technology, vol. 22, no. 6, pp. 879-883, 2012.

[45] J. Wei, H. Qin, and D. Wang, "Seepage characteristics of coal mass containing gas considering moisture effect in loadingunloading confining pressure test," Journal of Mining and Safety Engineering, vol. 31, no. 6, pp. 987-994, 2014.

[46] Z. Liu, Z. Li, Y. Yang, and H. Ji, "Experimental study of effect of water on sorption and radial gas seepage of coal," Chinese Journal of Rock Mechanics \& Engineering, vol. 33, no. 3, pp. 586593, 2014.

[47] C. Jiang, G. Yin, J. Xu, S. Peng, and W. Li, “The effect of original moisture content in coal beds on coal and gas outburst risk level," Journal of Chongqing University, vol. 37, no. 1, pp. 9195, 2014.

[48] D. Chen, Z. Pan, J. Liu, and L. D. Connell, "Modeling and simulation of moisture effect on gas storage and transport in coal seams," Energy \& Fuels, vol. 26, no. 3, pp. 1695-1706, 2012.

[49] J. Jing, W. Liang, B. Zhang, and L. Li, "Experimental investigation on coal permeability under water injection," Journal of Taiyuan University of Technology, vol. 47, no. 4, pp. 450-454, 2016.

[50] Z. Gao and W. Yang, "Adsorption mechanism of water molecule on different rank coals molecular surface," Journal of China Coal Society, vol. 42, no. 3, pp. 753-759, 2017.

[51] B. Lin and S. Zhou, "Experimental investigation on the permeability of the coal samples containing methane," Journal of
China University of Mining \& Technology, vol. 16, no. 1, pp. 21-28, 1987.

[52] Z. Feng, Y. Zhao, and Z. Wen, "Percolation mechanism of fractured coal rocks as dual-continua," Chinese Journal of Rock Mechanics and Engineering, vol. 24, no. 2, pp. 236-240, 2005.

[53] G. Yin, C. Jiang, J. Xu, L. Guo, S. Peng, and W. Li, “An experimental study on the effects of water content on coalbed gas permeability in ground stress fields," Transport in Porous Media, vol. 94, no. 1, pp. 87-99, 2012.

[54] S. Prion and K. A. Haerling, "Making sense of methods and measurement: Pearson product-moment correlation coefficient," Clinical Simulation in Nursing, vol. 10, no. 11, pp. 587-588, 2014.

[55] L. E. Toothaker, "Multiple regression: testing and interpreting interactions," Journal of the Operational Research Society, vol. 45, no. 1, pp. 119-120, 1994.

[56] C. Coulton and J. Chow, "Interaction effects in multiple regression," Journal of Social Service Research, vol. 16, no. 1-2, pp. 179-199, 1993.

[57] H. K. Chan, R. W. Y. Yee, J. Dai, and M. K. Lim, “The moderating effect of environmental dynamism on green product innovation and performance," International Journal of Production Economics, vol. 181, pp. 384-391, 2016. 